\title{
Clinico-epidemiological profile of snake bite in children in a tertiary care hospital, South India
}

\author{
Suganthi $V^{1}$, Santhi $K^{2}$, Nandhini $S^{3}$ \\ ${ }^{1}$ Dr. Suganthi V., Professor and HOD, Department of Pediatrics, Government ESI Medical College and Hospital, \\ Coimbatore, ${ }^{2}$ Dr. Santhi K, Junior Resident, Department of Pediatrics, Coimbatore Medical College, Coimbatore, \\ ${ }^{3}$ Dr. Nandhini S., Junior Resident, Department of Pediatrics, Coimbatore Medical College, Coimbatore, Tamil Nadu, \\ India.
}

Corresponding Author: Dr. Santhi K, 222, Salem Main Road, Vennaimalaipatti, Vennaimalai post, Karur 6. E-mail drksanthimbbs@gmail.com

\begin{abstract}
Introduction: A high incidence of snake bite envenomation is observed in India, due to rapid urbanization and deforestation. Snake bite is a life-threatening conditionand remains a significant cause for hospital admissions in paediatric age group. Because of their smaller body mass, they have rapid systemic envenomation and high mortality rate. Methods: This is a descriptive type of study about clinical and epidemiological profile of snake bite cases in pediatric age group and also included unknown bites with features of snake bite envenomation. This was done for the period of one year from July 2015 to June 2016. Data about age, sex, bitesite, clinical features, complications, management and outcome were collected and analysed. Results: The study included 54 cases of snake bite victim. Majority were boys $(64.8 \%)$. The common age group affected was 5-10 years (59\%). Lower extremities were the most common site of bites (85\%). $42.6 \%$ of cases had clinical features within 2 to 6 hours of snake bite. Bite admission interval was 6 hours. Prehospital treatment was employed in $10.3 \%$ of patients. In our study, $38.9 \%$ of victimspresented with snake bite of unknown species, 39\% known species of snakes and $22.1 \%$ were cases of envenomation, where the snake was not visualized. The commonest identified species were viper bite $(n=11,20.4 \%)$, followed by rat snake ( $n=7$, $13 \%)$ and krait $(n=3,5.6 \%) .23(42.6 \%)$ cases had dry bite. About 12 (22\%) children had local cellulitis; 12 (22\%) had combined cellulitis and hemotoxicity; 7 (13\%) had neurotoxicity. In our study polyvalent Anti snake venom (ASV) was used in $55.6 \%$ of cases and $18.5 \%$ of victims developed hypersensitivity reactions to ASV. The case fatality was $11.1 \%$ and Krait was the main cause of mortality. Conclusions: Of the children presented with snake bite envenomation, the snake was visualized in majority of cases. Most of them developed clinical features in 2 to 6 hours ofbite. Cellulitis was the commonest presentation and polyvalent ASV was used for treatment. Neurotoxic Krait bite was the commonest cause of mortality.
\end{abstract}

Keywords: Complications, Epidemiology, India, Pediatric, Snake bites

\section{Introduction}

Snake bite envenomation is a neglected but important public health problem in rural areas of South Asia, South East Asia and Sub Saharan Africa [1]. WHO estimates the problem as 4,21,000 envenomation and 20,000 deaths per annum. The same report also suggest that the burden may be ashigh as 1,841,000 envenomation and 94,000 deaths globally [2]. It is a well-known occupational hazard in rural part of India, where farming is the main occupation. India is reported to have highest number of deaths due to snake bites in

\footnotetext{
Manuscript received: $7^{\text {th }}$ April 2018

Reviewed: $17^{\text {th }}$ April 2018

Author Corrected: $24^{\text {th }}$ April 2018

Accepted for Publication: $30^{\text {th }}$ April 2018
}

the world [3]. In India 1,19,368 envenomation and 1559 death per annum were reported in 2011 [4]. In India, 236 species of snakes have been reported [5]. These include venomous snakes of the family Elapidae and Viperidae. Viperidae are represented by true viper and pit vipers [6].

The family of Elapidaehas 17 species, which includes cobras, king cobras, kraits and coral snakes. The spectacled cobra (Najanaja) is one of the commonest snake in India. Kraits are nocturnal snakes which enter human dwelling at night in search of prey and many victims are bitten in their sleep. 
The prevalence of different snakes varies in different geographical areas of the country. As a result, the clinical management and clinical practices vary.

People in countries like India prefer traditional healers rather than trained doctors mainly because of ignorance and monetary issues [7].

Since complications of snake bite develop rapidly and irreversibly, medical treatment must be prompt and appropriate [8].

WHO prescribes a standard protocol for treating snake bites in South East Asian countries [9].

A national protocol for management of snake bites in India is also in place [10]. ASV is a scarce and costly commodity.

There is a need to understand venom composition as per geographic variation in species. The data on the epidemiology of snake bites are sparse in India [11].

The current study was conducted with objective of assessing the clinical and epidemiological profile of pediatric snake bite victims, admitted to a tertiary care hospital in South India.

\section{Materials and Methods}

Place of study: The present study was carried out in the department of pediatrics of a tertiary care teaching hospital at Coimbatore.

Type of study: This is a descriptive type of observational study, conducted during the period of July 2015 to June 2016.

\section{Results}

54 cases of snake bite were admitted in pediatric intensive care unit (PICU) during the study period. It was about $5 \%$ of total PICU admissions. Majority of cases were male children $(n=35,64.3 \%)$.

Maximum incidence of snake bite occurred in the age group of 5 to $10(n=32,59.3 \%)$.

Lower extremities were the site of bite inmore than three fourth of the cases $(n=46,85.2 \%)$.

Pre hospital treatment was employed in $10.3 \%$ of the patients (Table 1$)$. In $12(22.2 \%)$ cases with acute envenomation, the offending agent was not visualized.

Among the snakes visualized, the species type was not identified in 21 (38.9\%) cases. The species were identified in another 21 cases.

The commonest identified species were viper bite $(n=11,20.4 \%)$, followed by ratsnake $(n=7,13 \%)$ and krait $(n=3,5.6 \%)$.
A prior approval was obtained from the institutional

Inclusion criteria: (1) age group 1 month to 12 years with history of snake bite, having noticed the offending snake, (2) doubtful history of snake bite, but with definitive acute symptoms and signs of local or

Exclusion criteria: (1) Bites due to other creatures (2) Doubtful cases of snake bite with no definitive history

Epidemiological and clinical data about age, sex, time and site of snake bite, type of offending agent or species

Detailed history and clinical examination were done and patient managed as per protocol.

All our snake bite patients were investigated with complete blood count, renal function tests, electrolytes, 20 minutes whole blood clotting time. ASV was given

All patients were studied for complications during hospital stay. Blood products transfusion, ventilator support and dialysis were carried out as when indicated.

Patients developing severe cellulitis were given appropriate antibiotics and referred to surgeon for

The duration of hospital stay and conditions at the time of discharge were noted. Study outcome was noted as discharge or death. ethics committee. 
Table-1: Epidemiological characteristics of snake bite.

\begin{tabular}{|c|c|c|}
\hline Characteristics & No. of patients & $\%$ \\
\hline \multicolumn{3}{|l|}{ Age distribution } \\
\hline $1-5$ years & 16 & 29.6 \\
\hline $5-10$ years & 32 & 59.3 \\
\hline$>10$ years & 6 & 11.1 \\
\hline \multicolumn{3}{|l|}{ Sex distribution } \\
\hline Boys & 35 & 64.8 \\
\hline Girls & 19 & 35.2 \\
\hline \multicolumn{3}{|l|}{ Bite site } \\
\hline Lower limb & 46 & 85.2 \\
\hline Upper limb & 6 & 11.1 \\
\hline Others & 2 & 3.7 \\
\hline \multicolumn{3}{|l|}{ Pre-Hospital Treatment } \\
\hline Wound distortion & 2 & 3.7 \\
\hline Tourniquet application & 3 & 5.6 \\
\hline Nil & 49 & 90.7 \\
\hline \multicolumn{3}{|l|}{ Type of Offending Agent } \\
\hline Viper bite & 11 & 20.4 \\
\hline Rat snake bite & 7 & 13.0 \\
\hline Krait bite & 3 & 5.6 \\
\hline Unknown snake bite & 21 & 38.9 \\
\hline Unknown bite & 12 & 22.1 \\
\hline
\end{tabular}

23 cases $(42.6 \%)$ developed clinical symptoms in 2-6 hours of bite. 23(42.6\%) cases had dry bite. About 12 (22\%) children had local cellulitis; 12 (22\%) had combined cellulitis and hemotoxicity; 7 (13\%) had neurotoxicity (Table 2). In our study, 13 cases $(24 \%)$ presented with coagulation abnormality. 2 cases $(3.7 \%)$ presented with acute renal failure.

Table-2: Clinical manifestations of snake bite.

\begin{tabular}{|c|c|c|c|c|c|c|}
\hline & Cellulitis & $\begin{array}{c}\text { Cellulitis and } \\
\text { hemotoxicity }\end{array}$ & Neurotoxicity & Dry bite & \multicolumn{2}{|c|}{ Total } \\
\cline { 3 - 7 } & 3 & 4 & & $\mathbf{n}$ & 11 & 20.4 \\
\hline Viper & & & 3 & 7 & 7 & 13 \\
\hline Rat snake & 2 & 6 & 1 & 12 & 21 & 38.9 \\
\hline Krait & 7 & 2 & 3 & & 12 & 22 \\
\hline $\begin{array}{c}\text { Snake bite with species } \\
\text { not identified }\end{array}$ & $\mathbf{1 2}$ & $\mathbf{1 2}$ & $\mathbf{7}$ & $\mathbf{2 3}$ & $\mathbf{5 4}$ & $\mathbf{1 0 0}$ \\
\hline Unknown bite & & & & & 3 \\
\hline Total & & & & & & \\
\hline
\end{tabular}

$\mathrm{n}=$ frequency of species

ASV was used in 55.6\% of cases and average vials of ASV used are 10-20 and 2 victims required less than 10 vials of ASV. $18.5 \%$ of cases who received ASV had reactions (Table 3). 
Table-3: ASV requirements and its adverse reactions.

\begin{tabular}{|c|c|c|c|c|c|c|c|}
\hline & \multirow[t]{2}{*}{ No ASV } & \multirow[t]{2}{*}{$<10$} & \multirow[t]{2}{*}{$10-20$} & \multirow[t]{2}{*}{$20-30$} & \multirow[t]{2}{*}{ Total } & \multicolumn{2}{|c|}{ ASV reactions } \\
\hline & & & & & & Yes & No \\
\hline & $\mathbf{n}$ & $\mathbf{n}$ & $\mathbf{n}$ & $\mathbf{n}$ & $\mathbf{n}$ & n & $\mathbf{n}$ \\
\hline Viper bite & 4 & - & 3 & 4 & 11 & 2 & 5 \\
\hline Rattle snakebite & 7 & - & & & 7 & - & - \\
\hline Krait bite & - & & 3 & & 3 & 1 & 2 \\
\hline $\begin{array}{c}\text { Snakebite where species } \\
\text { not identified }\end{array}$ & 13 & 1 & 5 & 2 & 21 & 1 & 20 \\
\hline Unknown bite & - & 1 & 7 & 4 & 12 & 1 & 11 \\
\hline Total & 24 & 2 & 18 & 10 & 54 & 10 & 44 \\
\hline
\end{tabular}

$\mathrm{n}=$ frequency of cases

In our study $88.8 \%$ of cases $(n=46)$ completely recovered without any sequelae. Case fatality rate was $11.1 \%$ and kraitbite was the main cause (Table 4).

Table-4: Outcome of snake bite.

\begin{tabular}{|c|c|c|c|c|}
\hline & & $\begin{array}{c}\text { Cured } \\
\mathbf{n}\end{array}$ & $\begin{array}{c}\text { Dead } \\
\mathbf{n}\end{array}$ & $\begin{array}{c}\text { Total } \\
\text { n }\end{array}$ \\
\hline & Viper bite & 11 & - & 11 \\
\hline \multirow{4}{*}{ 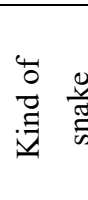 } & Rat snake bite & 7 & - & 7 \\
\hline & Krait bite & 1 & 2 & 3 \\
\hline & Snake bite species not identified & 19 & 2 & 21 \\
\hline & Unknown bite & 10 & 2 & 12 \\
\hline \multicolumn{2}{|r|}{ Total } & 48 & 6 & 54 \\
\hline
\end{tabular}

$\mathrm{n}=$ frequency of cases

\section{Discussion}

The study included 54 children with snake bite envenomation. Majority were in the age group between 5 to 10 years. Ina study by Kshir sagar VY [12] about snake bite envenomation in 162 children in Maharashtra, children over 5 years were more commonly involved. In the study conducted by Helen $\mathbf{J}$ Mead [13] about clinical profile of snake bite envenomation in 156 children, the mean age was 6 years.

The epidemiological character in our study showed that more common victims in children were males when compared to females. Similar observation was made by Karunanayake RK [14] in a study on 54 children with snake bite envenomation.

The most frequently bitten site in our study was the lower extremity $(85.2 \%)$. Similar observations have been made in other studies $[12,14]$. But the study done by Aktar F [15] on snake bite envenomation in 151 children, most common location of bite was right forearm in $61.6 \%$ of children. Bites to the extremities occur in children who unintentionally disturb a snake while playing outside their houses or in the fields.

In our study, pre hospital treatment like wound distortion and tourniquet application were employed in $10.3 \%$ of patients. In the study done by Karunanayake RK [14], tourniquet application and native treatment were done as pre-hospital treatment in $16 \%$ children.

The initial first aid of the victim is to reduce the spread ofvenom and transfer to appropriate health facility. The methods like tourniquet application, sucking out the poison are to be discouraged. In this study, about $42.6 \%$ of cases had clinical features within two to six hours bite. The study by Kshirsagar VY [12] in rural India had similar results. Symptoms and signs of envenomation vary according to species and evolve over time. Hence frequent clinical examinations are very important. 
Most common nonpoisonous snake in our area was rat snake. Among the identified poisonous snake bites, Viper was the commonest, about $20.4 \%$. Kulkarni ML [16] did a study on snake venom poisoning in 633 children in CentralKarnataka, in which Viper was the most common poisonous snake involved in $80 \%$. Most venomous snakes belong to the families Elapidae or Viperidae.

Among the 54 cases admitted in the hospital, 23 (43\%) victims presented as dry bite.Thisreflects that many victims got panicked andwere brought to emergency department, although they did not have poisonous manifestations. This also reflects the increased awareness about snake bite mortality among general population.

About 12 (22\%) children had local cellulitis; 12 (22\%) had combined cellulitis and hematotoxicity; 7 (13\%) had neuro toxicity. The local effects manifested as swelling, blistering and ecchymosis. A positive 20minute whole blood clotting testwas an indication for antivenom administration.

The findings of neurotoxicity were ptosis, limb paralysis and respiratory failure. In a study done by Sankar J [17] on snake envenomation among 110 children in a teaching hospital, 64.2\% had predominantly haematotoxic envenomation, $18 \%$ neurotoxicity and $16 \%$ local involvement.

Acute renal failure was seen in $3.7 \%$ children in our study whereas a higher percentage of $18 \%$ was observed in the study by Adhisivam B [18].

Anti snake venom (ASV) was administered in 30 (55\%) children. $60 \%$ of them required 10 to 20 vials of ASV. In a study done by Gautam $\mathrm{P}$ [19] on snake envenomation in 60 children at Himachal Pradesh, the average number of ASV vials used were about 20 .

The existing polyvalent ASV is efficacious against the 4 major species (Cobra, krait, Russel viper, saw scaled viper). However, there occurs envenomation due to a number of other species also, like Hump-nosed pit viper, which usually doesn't respond adequately to existing antivenoms.

In a prospective study done by Ariaratnam CA [20] on snake bite envenoming in 860 patients, $35 \%$ were bitten by Hump-nosed pit viper, in which available ASV was ineffective. In our study, Hump-nosed pit viper was not identified.
About 5 (18\%) children developed anaphylactic reactions in our study. All of them responded to antihistamines, steroids and adrenaline. Seneviratne SL [21] did a study on use of antivenom serum in snake bite in 466 patients in Gampaha district, Sri Lanka. He observed that upto $55 \%$ of patients treated with ASV developed one or more adverse effects such as pyrogenic reactions, anaphylactoid reactions or late serum sickness. A review of snake bite in South Asia done by Alirol E [22] observed that severe drug reactions were under-reported.

The rates of allergic reactions varies with different antivenom preparations. Antivenom should be administered in envenomation victims, with resuscitation equipment and medications available to treat anaphylaxis.

In our study, case fatality rate was $11.1 \%$ and krait bite was the main cause for mortality. These children were brought to our facility late, after 6 hours of bite with respiratory paralysis.

\section{Conclusion}

Snake bite still remains a major public health problem in this part of the world. Knowledge must be imparted regarding the presentation of snake bites through community health programmes. This time limiting medical emergency should be dealt by aggressive management of the ABC's and immediate transfer of the victim to the hospital for neutralization of the venom by ASV. Improper first aid, delay in reaching hospital, unavailability of ASV worsens the outcome. Several RCT has to be done in concern with the rationale use of ASV. ASV availability should be made free to all victims in government and private hospitals. Issues to be emphasized in future includes

* A national programme is to be initiated regarding this neglected emergency

* Proper antidotes to counteract the venom reactions

* Spetific ELISA kit biomarkers to detect venom antigens in blood

* Importance of region specific monovalent ASV production is needed.

What is already known: Snake bite is a time limiting medical emergency

What this study adds: Signsand symptoms of envenomation vary among different species and evolve over time. 
Abbreviations used: ASV-Anti snake venom, ELISAEnzyme linked immunosorbent assay, PICU- Pediatric intensive care unit, RCT- Randomized controlled trial, WHO - World Health Organization.

Authors contribution: SV: Concept, Design of the work, data analysis, drafting the work, editing, revising it and final approval of the article. SK: Concept, Design of the work, Data acquisition, data analysis. NS: Data acquisition, data analysis.

Funding: Nil, Conflict of interest: None initiated, Perission from IRB: Yes

\section{References}

1. WHO. (2010). Working to overcome the global impact of neglected tropical diseases. Retrieved from who. int/ neglected diseases/2010 report

2. National snakebite management protocol, India. (2008). [online] Available at www://mohfw.nic.in (Directorate General of Health and Family Welfare, /Ministry of Health and Family Welfare, India).

3. Chippaux JP. Snake-bites: appraisal of the global situation. Bull World Health Organ. 1998; 76 (5): 515-24.

4. Central Bureau of Health intelligence-India. National Health Profile (NHP) of India-2011. Health status indicators. Cases and deaths due to snakebites in India. Retrieved from cbhidghs.nic.in/index1.asp

5. Mohapatra B, Warrell DA, Suraweera W, Bhatia P, Dhingra N, Jotkar RM, Rodriguez PS, Mishra K, Whitaker R, Jha P; Million Death Study Collaborators. Snakebitemortality in India: a nationally representative mortality survey. PLo SNegl Trop Dis.2011 Apr 12;5 (4): e 1018. doi: 10.1371/journal. pntd.0001018.

6. Warrell DA. Snake bite: A neglected problem in twenty-first century India. Natl Med J India. 2011; $24: 321-4$.

7. Warrell DA, Gutiérrez JM, Calvete JJ, et al. New approaches and technologies of venomics to meet the challenge of human envenoming by snake-bites in India. Indian. J Med Res 2013;138:38-59

8. World Health Organization (2007). Rabies and Envenomings. A Neglected Public Health Issue: Report of a Consultative Meeting. Geneva: WHO. $<$ http:// www. who.int/bloodproducts/animal_sera/Rabies.pdf $>$.
9.Warrell DA. WHO/SEARO guidelines for the clinical management of snakebite in the Southeast Asian region. Southeast Asian J Trop Med Public Health. 1999; 30: $1-85$

10. Morais V, Massaldi H. Economic evaluation of snake antivenom production in the public system. $\mathrm{J}$ Venom Anim Toxins incl Trop Dis. 2006; 12 (3): 497- 511.

11. Kasturiratne A, Wickremasinghe AR,de Silva N, et al. The global burden of snakebite: a literature analysis and modeling based on regional estimates of envenoming and deaths. PLoS Med. 2008: 5 (11): e218.

12. Kshirsagar VY, Ahmed M, Colaco SM. Clinical Profile of Snake Bite in Children in Rural India. Iranian J Pediatrics. 2013;23(6):632-6.

13. Mead HJ, Jelinek GA. Suspected snakebite in children: a study of 156 patients over 10 years. Med J Aust. 1996 Apr 15;164(8):467-70.

14. Karunanayake RK, Dissanayake DMR, Karunanayake AL. A study of snake bite among children presenting to a paediatric ward in the main Teaching Hospital of North Central Province of Sri Lanka. BMC Res Notes. 2014;7:482.

15. Aktar F, Aktar S, Yolbas I, Tekin R. Evaluation of Risk Factors and Follow-Up Criteria for Severity of Snakebite in Children. Iran J Pediatr. 2016 Jul 10;26 (4): e5212. e Collection 2016 Aug.

16. Kulkarni ML, Anees S. Snake venom poisoning: experience with 633 cases. Indian Pediatr. 1994 Oct;31 (10) : 1239-43.

17. Sankar J, Nabeel R, Sankar MJ, Priyambada L, Mahadevan S (2013) Factors affecting outcome in children with snake envenomation: a prospective observational study. Arch Dis Child 98: 596-601. doi: 10.1136 / archdischild-2012-303025.

18.Adhisivam B,Mahadevan S.Snakebite envenomation in India: a rural medical emergency. Indian Pediatr. 2006 Jun;43(6):553-4.

19. Gautam P, Sharma N, Sharma M, Choudhary S. Clinical and demographic profile of snake envenomation in Himachal Pradesh, India. Indian Pediatr. 2014;51:934-5 
20. Ariaratnam CA, Thuraisingam V, Kularatne SA, Sheriff MH, Theakston RD, de Silva A, Warrell DA. Frequent and potentially fatal envenoming by humpnosedpit vipers (Hypnalehypnale and H. nepa) in Sri Lanka: lack of effective antivenom. Trans R Soc Trop Med Hyg. 2008 Nov;102(11):1120-6. doi: 10.1016/j. trstmh. 2008. 03.023. Epub2008 May 2.

21. Seneviratne SL, Opanayaka CJ, Ratnayake NS, Kumara KE, Sugathadasa AM, Weerasuriya N,
Wickrama WA, Gunatilake SB, de Silva HJ. Use of antivenomserum in snake bite: a prospective study of hospital practice in the Gampahadistrict. Ceylon Med J. 2000 Jun;45(2):65-8.

22. Alirol E, Sharma SK, Bawaskar HS, Kuch U, Chappuis F (2010) Snake Bite in South Asia: AReview. PLo SNeg1 Trop Dis4 (1):e603.https://doi.org/10. 1371/ journal. pntd.0000603

\section{How to cite this article?}

Suganthi V, Santhi K, Nandhini S. Clinico-epidemiological profile of snake bite in children in a tertiary care hospital, South India. Int J Pediatr Res. 2018;5(4):196-202. doi:10.17511/ijpr.2018.i04.07. 